\title{
Correction to: Effects of Heat Input on Weld-Bead Geometry, Surface Chemical Composition, Corrosion Behavior and Thermal Properties of Fiber Laser-Welded Nitinol Shape Memory Alloy
}

Susmita Datta, Mohammad Shahid Raza, Partha Saha, and Dilip Kumar Pratihar

\section{Correction to:}

\section{JMEPEG}

https://doi.org/10.1007/s11665-019-04077-0

Please note that the correct sequence of authors is "Susmita Datta, Mohammad Shahid Raza, Partha Saha, Dilip Kumar Pratihar".
Publisher's Note Springer Nature remains neutral with regard to jurisdictional claims in published maps and institutional affiliations.

The original article can be found online at https://oi.org/10.1007/ s11665-019-04077-0.

Susmita Datta, Mohammad Shahid Raza, Partha Saha, and Dilip Kumar Pratihar, Department of Mechanical Engineering, Indian Institute of Technology Kharagpur, Kharagpur, West Bengal, India. Contact e-mail: psaha@mech.iitkgp.ernet.in. 